\title{
Brechts Lehrstücke
}


Klaus-Dieter Krabiel

\section{Brechts Lehrstücke}

Entstehung und Entwicklung eines Spieltyps

Verlag J. B. Metzler

Stuttgart • Weimar 
Die Umschlagabbildung zeigt eine Szene aus der Uraufführung der »Maßnahme« am 13.12.1930 in der Berliner Philharmonie. Der Abdruck erfolgt mit freundlicher Erlaubnis vom Bertolt Brecht Archiv in Berlin.

Die Deutsche Bibliothek - CIP-Einheitsaufnahme

\section{Krabiel, Klaus-Dieter:}

Brechts Lehrstücke : Entstehung und Entwicklung eines Spieltyps / Klaus-Dieter Krabiel. - Stuttgart ; Weimar :

Metzler, 1993

(Metzler-Studienausgabe)

ISBN 978-3-476-00956-2

ISBN 978-3-476-00956-2

ISBN 978-3-476-03504-2 (eBook)

DOI 10.1007/978-3-476-03504-2

Dieses Werk einschließlich aller seiner Teile ist urheberrechtlich geschützt. Jede Verwertung außerhalb der engen Grenzen des Urheberrechtsgesetzes ist ohne Zustimmung des Verlages unzulässig und strafbar. Das gilt insbesondere für Vervielfältigungen, Übersetzungen, Mikroverfilmungen und die Einspeicherung und Verarbeitung in elektronischen Systemen.

(C) 1993 Springer-Verlag GmbH Deutschland

Ursprünglich erschienen bei J. B. Metzlersche Verlagbuchhandlung

und Carl Ernst Poeschel Verlag GmbH in Stuttgart 1993 
Für Christine 
Die Avantgarde

der dadaismus

der expressionismus

die neue sachlichkeit

das zeitstück

die gefrorene musik, die konzertante musik, die gebrauchsmusik, das massenlied, das lehrstück die revue, der rote faden, der in szene gesetzte aphorismus, die gespielte losung wir kritisierten die zeit und die zeit kritisierte uns

(B. Brecht, um 1938[1])

Ich wurde ein wenig doktrinär, weil ich dringend Belehrung brauchte.

(B. Brecht, 1938[2]) 


\section{Inhalt}

Einleitung

I. Der Lindberghflug/Lehrstück - Deutsche Kammermusik

Baden-Baden 1929

1. Die Krise der Neuen Musik und die Gebrauchsmusikbewegung

(Donaueschingen/Baden-Baden 1921-1929)

2. Gebrauchswert/Lehrwert: Aspekte der frühen Ästhetik Brechts (1925-1929)

3. Der Lindberghflug - ein $\mathrm{R}$ a d i o h ö r s p i e 1

a. Kurt Weill. Rundfunk und Neue Musik/Probleme funkeigener Musik

b. Bertolt Brecht. Gebrauchswert des Rundfunks (die erste Phase der Radiotheorie)

c. Lindbergh: Entstehung, Quellen, erste Textfassung

d. Vorbereitung eines Radioexperiments/Reflexionen über funktechnisch reproduzierte Musik

e. Brecht/Weill/Hindemith: Der Lindberghflug. Text, Vertonung ........ 39

f. Uraufführung/Brechts Radiodemonstration/Ursendung .................... 43

g. Der Lindberghflug im Urteil der Kritik ............................................. 48

4. Brecht/Hindemith: Lehrstück - Fragment eines $\mathrm{G}$ e m e i n -

$\mathrm{sch}$ a f $\mathrm{ts} \mathrm{s}$ i i $\mathrm{ls}$

a. Paul Hindemith. Spielmusik/Gemeinschaftsmusik ......................... 52

b. Die Entstehung des Lehrstücks .....................................................

c. Technischer und sozialer Fortschritt/Gemeinschaft als Problem: Text, Vertonung

d. Erste Textdrucke/Anmerkungen zum Lehrstück .............................. 62

e. Der programmierte Skandal: Die Uraufführung ................................. 64

f. Publizistische Aufarbeitung eines Skandals: Die Badener Aufführung im Spiegel der Kritik

g. Positionen, Verhandlungen/Hindemiths Spielanweisung/Der Druck der Partitur

h. Nach-Spiele, Kontroversen, Einsprüche: Lehrstück-Aufführungen 1930-1933 
II. Brecht/Weill: Der neue Lindberghflug - die Schulfassung der Kantate 81

1. Kurt Weills Kantate für Soli, Chor und Orchester .................................. 81

a. Entstehung: Dissonanzen, taktische Züge, ein Interview ................. 81

b. Text und Vertonung ...................................................................... 85

c. Weills Notiz zum >Lindberghflug ‘............................................ 86

2. Das Textbuch zur Uraufführung ........................................................ 87

a. Brechts Anmerkungen zum Lindberghflug ................................. 87

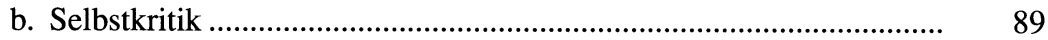

3. Die Uraufführung in der Krolloper/Pressekritik .................................. 91

4. Aufführungen/Sendungen 1930-1932 .............................................. 93

III. Der Flug der Lindberghs/Das Badener Lehrstück vom Einverständnis (1930) - Versuche, 〉Experimente<, Kontroversen

1. Der Begriff >Lehrstück $<$ : Erste Belege/Typusbegriff und Modewort/ Mißverständnisse

2. Vom Gebrauchsstandpunkt zur Analyse des Verwertungsproblems/ Der >Experiment $<$-Begriff der Versuche

3. Der Flug der Lindberghs - ein Radiolehrstück für Knaben und Mädchen

a. Selbstkorrektur: Die Textfassung der Versuche .............................. 102

b. Die Erläuterungen zum Flug der Lindberghs: Das Radiolehrstück als $>$ Experiment<

c. Brechts Frankfurter Rede Der Rundfunk als Kommunikationsapparat (November 1930)/Diskussionen, Wirkungen

d. Aufführungen seit 1945/Der Ozeanflug (1950) .............................. 113

4. Das Badener Lehrstück vom Einverständnis ......................................... 115

a. Die Textfassung der Versuche ....................................................... 115

b. Brechts Anmerkung: Replik auf Hindemiths Spielanweisung .......... 122

5. Musik und Gesellschaft/Kontroversen um die Gebrauchsmusik .......... 124

a. Theodor W. Adornos Kritik musikalischer Gebrauchsformen .......... 124

b. Adorno - Brecht: Ästhetische Autonomie oder experimentelle Gebrauchskunst?

c. Paul Hindemiths Selbstverständnis als Musiker/Ästhetische Positionen im Schatten der NS-Diktatur

IV. Brecht/Weills S c hul o p e r Der Jasager

1. Kurt Weill. Gebrauchsmusik für die Schule .......................................... 133

2. Die Entstehung des Jasager ................................................................... 134

3. Quellen, Vorlagen ............................................................................ 135

a. Das japanische Nô-Spiel Tanikô ...................................................... 135

b. Arthur Waley: Tanikō. (The Valley-Hurling) .................................... 138

4. Der Jasager (1930): Text und Musik .................................................. 139

5. Die Uraufführung …………………................................................... 145

6. Kontroversen um die Schuloper ..................................................... 147 
7. Überprüfung des Jasager: Diskussionen an der Karl-Marx-Schule in Berlin-Neukölln

8. Der Jasager/Neufassung (1931) ........................................................ 152

9. Die Erstaufführung der Neufassung in der Karl-Marx-Schule .............. 154

10. Der Neinsager (1931)/Aufführungen seit 1945 .................................. 155

V. Brecht/Eisler: Die Maßnahme - ein p o lit is c he s L e h r s t ü k 158

1. Ein neuer Mitarbeiterkreis entsteht ................................................... 158

2. Hanns Eisler: »Die Kunst als Lehrmeisterin im Klassenkampf «/ Zur Situation der deutschen Arbeitersängerbewegung .......................... 160

3. Erste Entwürfe: Der Jasager (Konkretisierung) ................................. 163

4. Kontroversen mit der >Neuen Musik Berlin 1930 _.............................. 164

5. Die Maßnahme (1930): Entstehung/Text und Vertonung ..................... 167

6. Das politische Lehrstück als proletarische Gebrauchs- und Gemeinschaftskunst ................................................................................ 180

7. Probenarbeit, Uraufführung, >kollektive Produktionsberatung< ‘............ 182

8. Die Maßnahme in der Pressediskussion .............................................. 185

9. Die Versuche-Fassung des Lehrstücks (1931) .................................... 190

a. Vergleichende Textanalyse ................................................................ 190

b. Abstraktheit im Lehrstück/Das problematische Opfermotiv ............. 195

c. Brecht/Eisler: Anmerkungen zur $>M a ß n a h m e / /$ Kritisches zur neueren Lehrstücktheorie

10. Die Spaltung der deutschen Arbeitersängerbewegung (1931)/

Aufführungen, Verbote, Kommentare (1932-1956)

Exkurs: Bei Durchsicht neuerer Analysen oder Die Kunst der Interpretation

VI. Die Ausnahme und die Regel - ein S c h u l s t ü c k ........................... 240

1. Entstehung: Von der chinesischen Quelle zum Lehrstück (1930-32) ... 240

2. Regeln, Ausnahmen und das Problem >vernünftigen $<$ Handelns: Textanalyse

3. Zur Aufführungsgeschichte/Paul Dessaus Vertonung (1948) ............... 252

VII. Die Horatier und die Kuriatier - Lehrstück über Dialektik (1935) ...... 259

1. Die Vorgeschichte: Der >Auftrag $</$ Streit mit Hanns Eisler ................... 259

2. Entstehung: Quellen, erste Entwürfe ................................................ 262

3. Kleine Schule der Dialektik. Textanalyse ........................................... 263

4. Brechts Anweisung für die Spieler ................................................... 269

5. $\gg$ Eigentlich fehlt ein Schlußkapitel « .................................................. 270

6. Kurt Schwaens Vertonung (1955)/Aufführungen ............................... 272

VIII. Spieltheoretische Reflexionen (1929-1956) ......................................... 277

1. Fragmente einer Theorie der Pädagogien (um 1929) ............................. 277

a. Theorie der Pädagogien ...................................................................... 277

Exkurs: Nachahmung und Kritik von >Mustern< ............................. 279 
b. Institution >Pädagogium< ............................................................ 281

c. Die Große und die Kleine Pädagogik ..............................................

d. Lehrstück und Theorie der Pädagogien ........................................... 284

2. Das Lehrstückkonzept: Kontinuität und Entwicklung (1932-1956) ...... 285

a. Die Jahre des Exils/Lehrstück und episches Theater ......................... 285

b. Zur Theorie des Lehrstücks ............................................................. $\quad 289$

c. Die Berliner Jahre ............................................................................ 292

IX. Holzwege. Positionen der Lehrstückforschung ....................................... 295

X. Anmerkungen zur neueren Spielpraxis/Zur Frage der Aktualität des Lehrstückmodells ...................................................................... 313

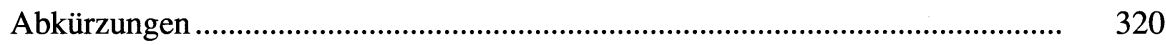

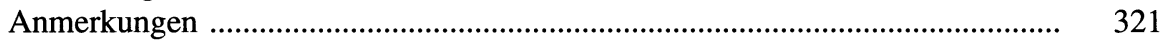

Literaturverzeichnis ……………………………………............................. 437

Personenregister …………………………………………………………..... 459 